\title{
Effects of the Manufacturing Conditions on the VOCs Emissions of Particleboard
}

\author{
Shijing Sun, ${ }^{\mathrm{a}}$ Zhongyuan Zhao, ${ }^{\mathrm{b}}$ and Jun Shen ${ }^{\mathrm{c}, *}$
}

\begin{abstract}
The volatile organic compounds (VOCs) emitted from wood-based panels are hazardous to indoor air quality. Usually, the VOCs are derived from the adhesive, chemical compounds, and wood components. However, there has been little research focusing on the effects of manufacture conditions on the VOC emissions. In this study, the effects of density, thickness, and resin content on total VOC (TVOC) and individual VOCs were investigated by the small chamber method and gas chromatography and mass spectrometry (GC/MS). The TVOC emission from the particleboard of each manufacturing condition decreased with extended exposure time. The higher density, thickness, and resin content of particleboard at each measured time caused higher concentrations of TVOC emissions. Most of the detected VOCs were aromatics. The esters, aldehydes, and ketones showed a high increasing level with increasing particleboard density, thickness, and resin content. This result indicated that these chemical compounds were most sensitive to changes in manufacturing conditions.
\end{abstract}

Keywords: VOC; Particleboard; Manufacturing condition; GC/MS

Contact information: a: College of Material Science and Engineering, Nanjing Forestry University, Nanjing 210037, China; b: College of Furnishings and Industrial Design, Nanjing Forestry University, Nanjing 210037, China; c: College of Material Science and Engineering, Northeast Forestry University, Harbin 150040, China; *Corresponding author: shenjunr@163.com

\section{INTRODUCTION}

As fossil resources decrease, the development of bio-based materials has been a significant topic in material science, but most bio-based advanced materials are still in the laboratory phase, a long way from application (Xiong et al. 2018; Wu et al. 2019; Zheng et al. 2019). Thus, traditional bio-based materials such as particleboard, plywood, and fiberboard are typically utilized in living environments (Navarrete et al. 2013; Du et al. 2014; Jiang et al. 2017). These materials are manufactured by bonding the wooden elements with synthetic resin adhesives, which are mostly synthesized by formaldehyde and other petroleum related chemical compounds; free formaldehyde and volatile organic compounds (VOCs) are emitted from these materials during their use. These chemical compounds often negatively affect human comfort and health (Brightman et al. 2008; Norback et al. 2009). For instance, released formaldehyde can cause irritation of the eyes and upper respiratory tract, and it has been classified as a Group 1 human carcinogen by the International Agency for Research on Cancer (Salthammer et al. 2010). Benzene is another carcinogen that can cause acute leukemia (Smith 2010). Hence, both the perspective of environmental sustainability and the consumer demand for non-hazardous materials contribute to the improvement of indoor air quality (IAQ).

Based on the research of this issue, there are two main directions; developing ecofriendly adhesive synthesized by harmless and renewable materials (Zhao et al. 2018a,b), 
and controlling VOC emissions. However, the VOCs emitted from bio-based materials are derived from both the adhesive and the wood components, so it is necessary to illuminate the VOC emission characteristics. There are some reports on the effects of environmental conditions (such as temperature, relative humidity (RH) and air exchange rate (AER)) on the VOC emissions (Kim and Kim 2015; Liang et al. 2015, 2016; Wolkoff 2018), but most of these studies are related to the emission of formaldehyde and total volatile organic compounds (TVOC), which limit the analysis of pollution source. In reports on the emission of individual VOCs from wood-based materials (Lin et al. 2009; Yrieix et al. 2010), the utilized materials were purchased from wood based material company, and this method ignored the manufacture conditions and storing time on VOCs emission. Thus, there is still a gap in the knowledge of VOCs emission characteristics and discipline, especially the relationship between emission of VOCs and manufacture conditions.

Based on previous research, the effects of hot pressing temperature and hot pressing time on the TVOC and VOCs emission were evaluated (Liu et al. 2010). However, some fabrication parameters can also affect the VOC emissions; therefore, the relationship between these conditions, TVOC emission, and VOCs needs to be clarified (Wang and Gardner 1999; Baumann et al. 1999; Jiang et al. 2002). In this study, the effects of particleboard density, thickness, and resin content on the TVOC and VOCs emission were studied by the method of dryers for collection, Tenax-TA tubes for absorption, thermal desorption, and gas chromatography and mass spectrometry (GC/MS) analysis.

\section{EXPERIMENTAL}

\section{Materials}

The Larix gmelinii wood particles were obtained from Langxiang Forestry Corp., Heilongjiang. The particles were dried at $105{ }^{\circ} \mathrm{C}$ until the moisture content was approximately $4 \%$. The average size of the particles was $18.7 \mathrm{~mm} \times 2.5 \mathrm{~mm} \times 0.3 \mathrm{~mm}$. The urea-formaldehyde (UF) resin was purchased from Bond Corp., Harbin, China. The UF resin was described as follows: $\mathrm{pH} 7.8$; curing time, $76.8 \mathrm{~s}$; formaldehyde content, $0.6 \%$; and solid content, $51.9 \%$. The resin mixed with $1.0 \%$ liquid paraffin as waterproof agent and $1.5 \%$ ammonium chloride as curing agent. Toluene-D8 (200 ng/ $\mu \mathrm{L}$; Toronto Research Chemicals, Toronto, ON, Canada) was prepared as internal standards that were dissolved with dichlormomethane (Dingshengxin Chemical Ltd., Tianjin, China).

\section{Manufacture of Particleboards}

The UF resin prepared by adding paraffin and $\mathrm{NH}_{4} \mathrm{Cl}$ was sprayed onto wood particles in a drum blender. The sprayed particles were mat-formed in a box with dimensions of $340 \mathrm{~mm} \times 320 \mathrm{~mm}$ for single layer particleboard. The mats were hot pressed at $140{ }^{\circ} \mathrm{C}$ and $2.5 \mathrm{MPa}$ for $5 \mathrm{~min}$. The particleboards were prepared with different density, thickness, and resin content. The detailed information of fabrication parameters is shown in Table 1, and three boards were manufactured under each condition. All particleboards were cut into $155 \mathrm{~mm} \times 155 \mathrm{~mm}$ dimensions. The ends and non-testing surfaces of the small particleboards were wrapped in clean aluminum foil, and the uncovered size was 125 $\mathrm{mm} \times 120 \mathrm{~mm}$ (the total exposed surface area for one sample was $150 \mathrm{~cm}^{2}$ ). The prepared specimens were sealed in polyethylene plastic bags and stored at $-30{ }^{\circ} \mathrm{C}$. 
Table 1. Manufacture conditions of the particleboards

\begin{tabular}{cccc}
\hline Variable & Density $\left(\mathrm{g} / \mathrm{cm}^{3}\right)$ & Thickness $(\mathrm{mm})$ & Resin Contents $(\%)$ \\
\hline Density & $0.60 / 0.65 / 0.70 / 0.75 / 0.80$ & 8 & 7 \\
Thickness & 0.70 & $8 / 12 / 16 / 19 / 22$ & 7 \\
Resin contents & 0.70 & 8 & $7 / 8 / 9 / 10 / 11$ \\
\hline
\end{tabular}

\section{VOCs Collection}

The room temperature was controlled to be $23{ }^{\circ} \mathrm{C} \pm 0.5^{\circ} \mathrm{C}$ by air conditioner, and the relative humidity was maintained at $50 \pm 5 \%$ with air humidifier. The particleboard specimen was quickly placed into a $15-\mathrm{L}$ clean dryer with a loading of $1.0 \mathrm{~m}^{2} / \mathrm{m}^{3}$. The dryer should be clean with distilled water and placed at ventilated condition. Three samples of each manufacture condition was analyzed. The board was kept in the dryer for $24 \mathrm{~h}$. An ANB3025 intelligent vacuum pump (New Weicheng Technology Ltd., Chengdu, China) was used to receive the gas emission from particleboards in the dryers. The carrier gas nitrogen was passed through, and the air inside of dryer was absorbed by Tenax-TA tubes (89 mm long with 6.4mm O.D., with $200 \mathrm{mg}$ of fillers inside to absorb VOCs including nhexane to n-hexadecane, Perkin Elmer, City, US), and the collection process maintained 2 $\mathrm{h}$ with $0.2 \mathrm{~L} / \mathrm{min}$ to receive $24 \mathrm{~L}$ sample volume. The experimental system is shown in Fig. 1. These absorbed VOCs were analysed as the first day emission from boards, and after collection the specimen was laid on room until next pre-design test day. The time intervals were set as $1,3,5,7,14,28$, and 60 days. The VOCs absorbed by Tenax-TA tube was injected with $2 \mu \mathrm{L}$ of $200 \mathrm{ng} / \mu \mathrm{L}$ Toluene-D8 for quantify the concentrations of VOCs. Afterwards, the VOCs with internal standard were desorbed for $5 \mathrm{~min}$ at $300{ }^{\circ} \mathrm{C}$ from the tube by thermal desorption system (Beifen Instrument Ltd., Beijing, China) followed by auto injecting $1 \mathrm{~min}$ into GC/MS.

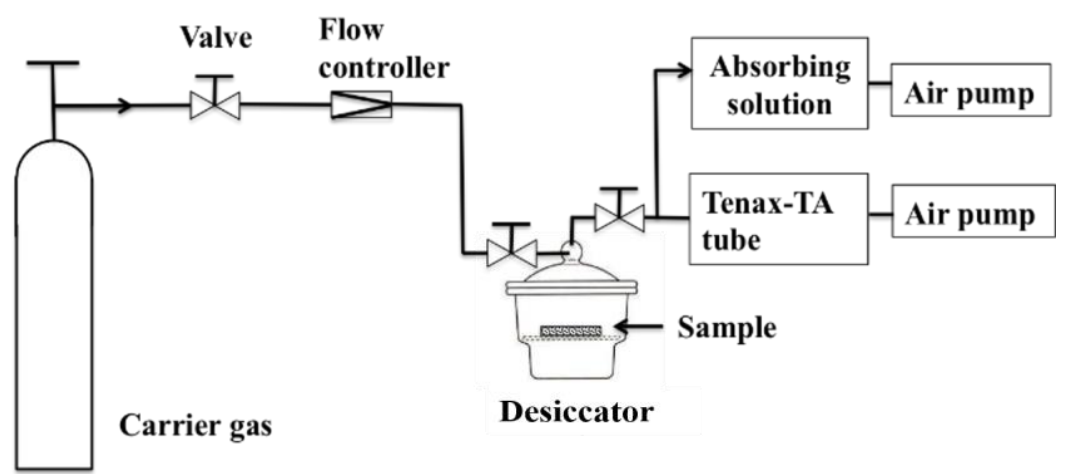

Fig. 1. Experimental system for volatile organic compounds (VOCs) collection from particleboard

\section{VOCs Analysis}

The components of VOCs emissions from particleboards were analysed using a GC/MS (Trace DSQ II, Thermo Scientific, Waltham, MA, USA) system consisting of a Trace gas chromatographic and a DSQ ${ }^{\circ} \mathrm{C}$ mass selective detector. TR-V1 capillary column was used with 0.25 millimetre ID, 30 meters and $1.4 \mu \mathrm{m}$ film thickness to separate the chemical compounds. The GC inlet temperature was set at $250{ }^{\circ} \mathrm{C}$ with a split ratio of 1:40. The GC oven temperature started at $40{ }^{\circ} \mathrm{C}$ and was held for 2 min. The temperature program was from 40 to $150{ }^{\circ} \mathrm{C}$ at a rate of $4{ }^{\circ} \mathrm{C}$ per minute and then heated to $250{ }^{\circ} \mathrm{C}$ at a rate of $10{ }^{\circ} \mathrm{C}$ per minute. The ionizer voltage of the MS detector was set at $70 \mathrm{eV}$, and the temperature was set to $230{ }^{\circ} \mathrm{C}$. The mass scan range was 40 to $450 \mathrm{amu}$. The carrier gas 
was high-purity helium with a flow rate at $1.0 \mathrm{~mL} / \mathrm{min}$. The interface temperature was set at $270{ }^{\circ} \mathrm{C}$. The compounds were identified by the retention time and comparison with mass spectra library. The number of carbon atoms between 6 and 16 with the similarity index more than 700 were selected. The concentrations of volatile components were quantified with the peak area of Toluene-D8. TVOC were calculated as the total concentration of each VOCs components.

\section{RESULTS AND DISCUSSION}

\section{Effects of Particleboard Density on the TVOC Emission}

Figure 2 shows the effects of the density of particleboards on TVOC emission from 1 to 60 exposure days. In general, the TVOC emission of each density particleboard decreased by prolonging the exposure time. However, the TVOC emissions of each density board on the first day were slightly lower than the results obtained from the third day. This was possibly due to the fact that the samples for detecting in the first day were taken out from refrigerator, so that the low temperature decelerated the release rate of TVOC. From 3 to 14 days, the TVOC of all the particleboards rapidly decreased with the increasing of the exposure time, but this emission level decreased from 14 to 60 days. At each measure time, the TVOC amount increased with increasing density of the particleboards. This phenomenon was attributed to the rising of density required more wood particles and resins, while the thickness and resin content were fixed. The highest TVOC volume was $481 \mu \mathrm{g} / \mathrm{m}^{3}$ at 3 days derived from $0.80 \mathrm{~g} / \mathrm{cm}^{3}$ density particleboard. In contrast, the TVOC emission from $0.60 \mathrm{~g} / \mathrm{cm}^{3}$ density particleboard $\left(341 \mu \mathrm{g} / \mathrm{m}^{3}\right)$ was $29 \%$ lower than highest density board. The lowest TVOC $\left(72.6 \mu \mathrm{g} / \mathrm{m}^{3}\right)$ was obtained from $0.60 \mathrm{~g} / \mathrm{cm}^{3}$ density particleboard at 60 days, which was $78 \%$ lower than the result of 3 days. However, the TVOC decrement of $0.80 \mathrm{~g} / \mathrm{cm}^{3}$ density particleboard from 3 to 60 days was $72 \%$, indicating that increasing the particleboard density decreased the TVOC emissions of the particleboard.

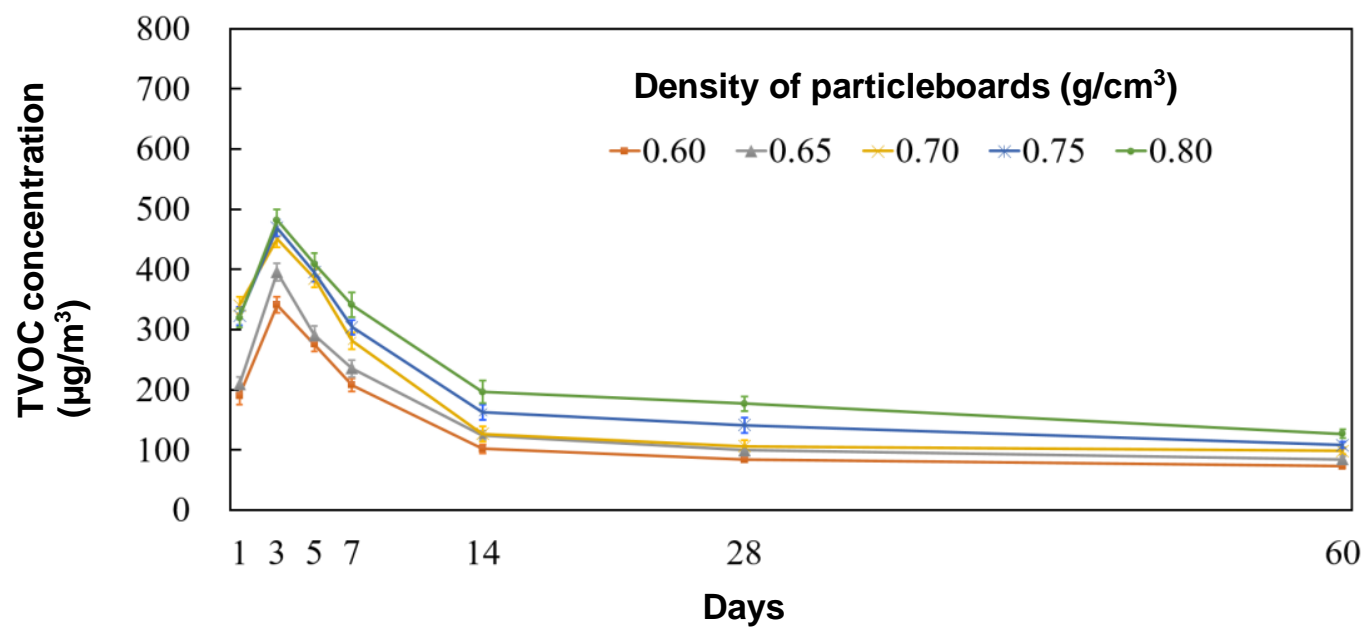

Fig. 2. Effects of particleboard density on the total volatile organic compounds emission

\section{Effects of Particleboard Thickness on the TVOC Emission}

Figure 3 shows the effects of particleboard thickness on TVOC emission during the exposure time from 1 to 60 days. A similar trend was obtained compared with the effects 
of particleboard density. As the exposure time was increased, the TVOC emission of each thickness type particleboard decreased from 3 to 60 exposure days. The highest TVOC emission obtained from the $16 \mathrm{~mm}$ thickness particleboard $\left(631 \mu \mathrm{g} / \mathrm{m}^{3}\right)$. Compared with the $16 \mathrm{~mm}$ thickness particleboard, the TVOC emission of $8 \mathrm{~mm}$ thickness particleboard decreased by $28 \%\left(450 \mu \mathrm{g} / \mathrm{m}^{3}\right)$. When the exposure time was longer than 28 days, the TVOC amount stabilized. At 60 days, the lowest TVOC emission was obtained from the 8 $\mathrm{mm}$ thickness boards $\left(98 \mu \mathrm{g} / \mathrm{m}^{3}\right)$, and compared with 3 days was $78 \%$ decreased. However, the decrement of the board with $16 \mathrm{~mm}$ thickness from 3 to 60 days was $67 \%$, which indicated that the thickness of the particleboard exhibited a negative correlation with TVOC emission efficiency. As the thickness increased, the TVOC amount increased at each detected days. Considering the density and resin content of each particleboard was constant $\left(0.7 \mathrm{~g} / \mathrm{cm}^{3}\right.$ and $7 \%$, respectively), this was due to the increasing of utilization of adhesive and wood particles.

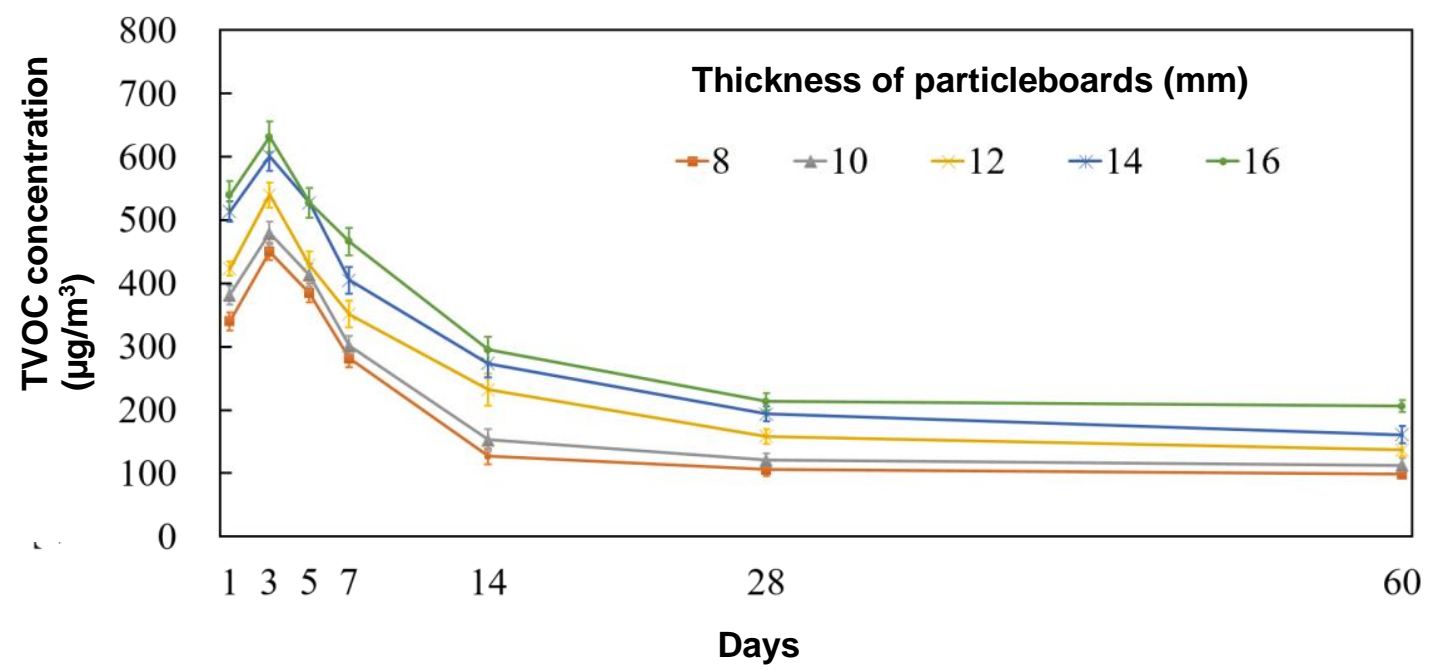

Fig. 3. Effects of particleboard thickness on the total volatile organic compounds (TVOC) emission

\section{Effects of Particleboard Resin Content on the TVOC Emission}

Figure 4 shows the effect of resin content of the particleboards on the TVOC emission. The TVOC trend in each specimen increased from 1 to 3 days, and then it decreased from 3 to 60 days. With increasing resin content, the TVOC emission increased at each exposure time, indicating a positive correlation between resin content and TVOC emission. The highest value was obtained from the board bonded with $11 \%$ resin content at 3 exposure days $\left(782 \mu \mathrm{g} / \mathrm{m}^{3}\right)$, and this value was $74 \%$ higher than the TVOC emission of $7 \%$ resin content $\left(450 \mu \mathrm{g} / \mathrm{m}^{3}\right)$. Notably, $782 \mu \mathrm{g} / \mathrm{m}^{3}$ was also the highest value among the 3 group experiments, indicating that the TVOC emission of the particleboard was most effected by the resin content. In addition, the TVOC decrement from 3 days of the board with $7 \%$ resin content was $78 \%$, but this value of the board with $11 \%$ resin content was $69 \%$, indicating that the resin content of the particleboard exhibited a negative correlation with TVOC emission efficiency. 


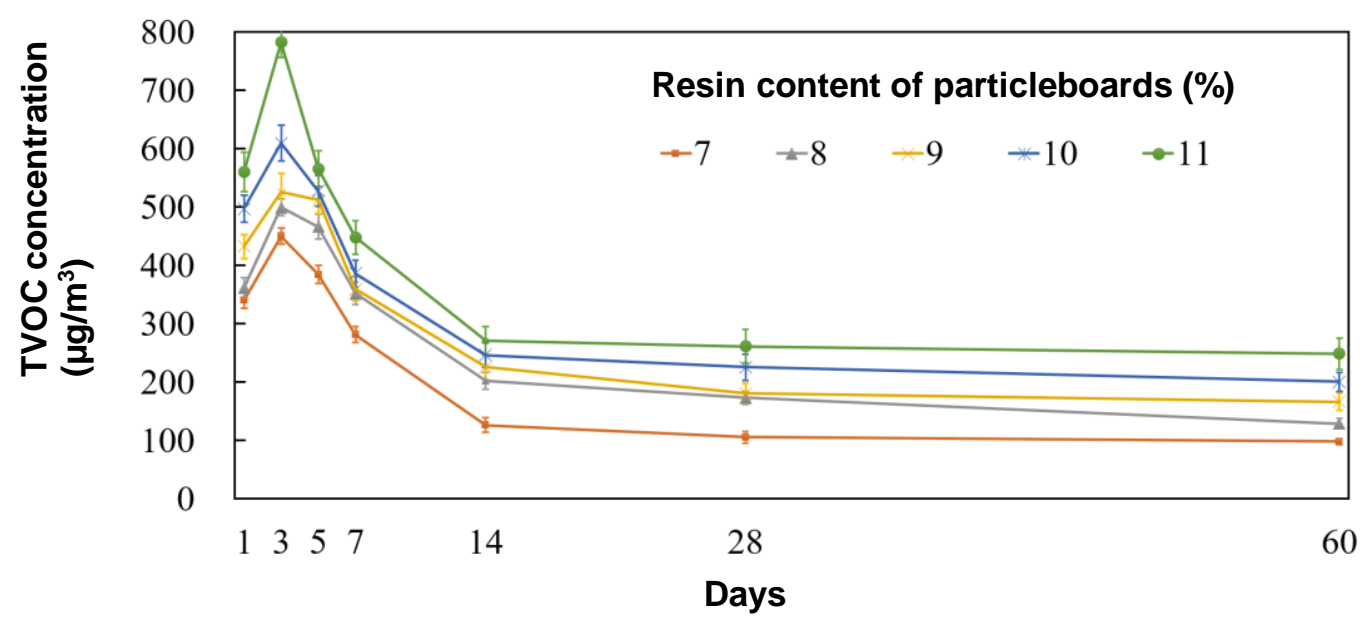

Fig. 4. Effects of particleboard resin content on the total volatile organic compounds emission

VOCs Analysis of the Particleboards Manufactured by Different Conditions

To identify the composition of TVOC, the chemical compounds were detected by the GC/MS method, and all the chemical compounds were classified into 7 types. Figure 5 shows these kinds of compounds concentrations of VOCs emission from five series of different density particleboards after exposing at room temperature 60 days. Aromatics (30 to $34 \%$ ) were the most component and followed by alcohols (17 to 27\%), alkanes (16 to $17 \%$ ), aldehydes (6 to $12 \%$ ), ketones ( 7 to $9 \%$ ), terpenes (6 to $10 \%$ ), and esters ( 3 to $5 \%$ ). As the density of particleboards increased, the amounts of each component increased, and this was caused by the same reason as for the increasing of TVOC. The levels of each type VOC emission along with density increases are shown in Table 2. Comparing with 0.60 $\mathrm{g} / \mathrm{cm}^{3}$ board, the concentration of ester compounds in $0.80 \mathrm{~g} / \mathrm{cm}^{3}$ density boards increased $233 \%$. The increasing levels in the second and third higher place were aldehydes (221\%) and terpenes (149\%).

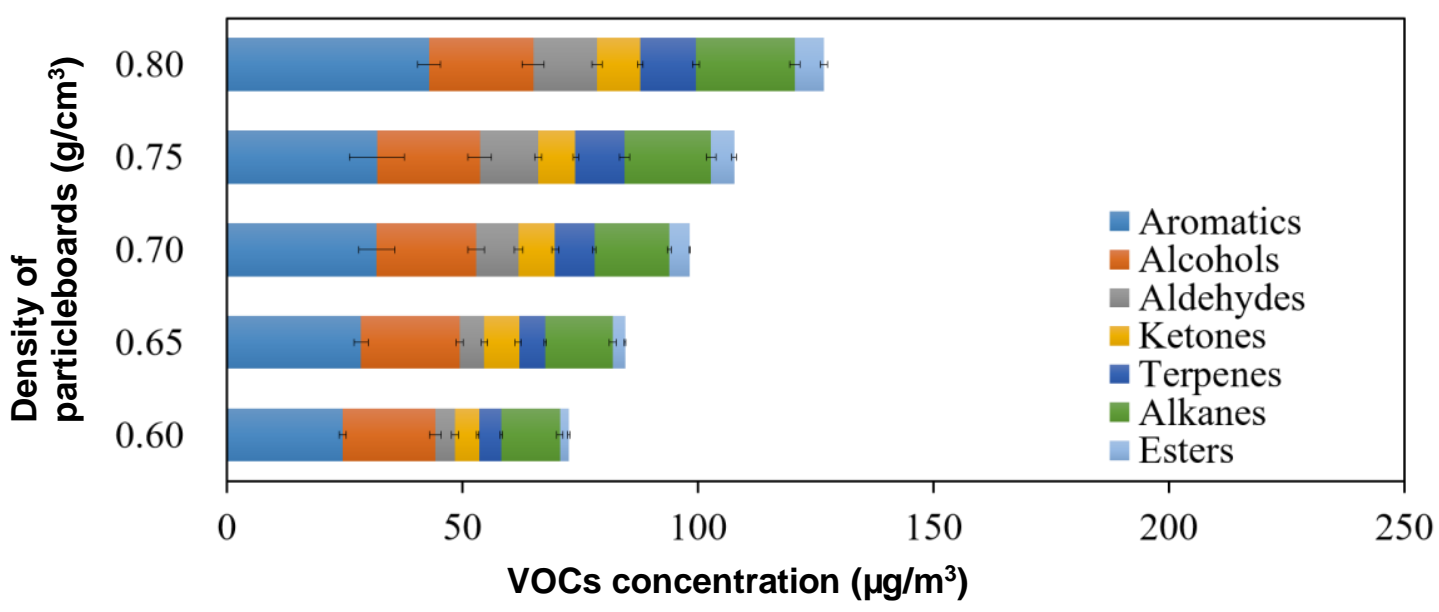

Fig. 5. Chemical compounds concentration of volatile organic compounds (VOCs) emission from five series of different density particleboards after exposure at room temperature for 60 days

Figure 6 shows the amount of VOCs emission from each thickness type particleboard with 60 days exposure time. The amounts of all compounds were increased by adding thickness, and this was attributed to the similar reason as for the increase of 
TVOC. The most abundant among the detected VOCs was aromatics, accounting for approximately $30 \%$ of TVOC, followed by alcohols (20 to 23\%), alkanes (14 to 16\%), aldehydes ( 9 to $13 \%$ ), terpenes ( 8 to $12 \%$ ), ketones (6 to $8 \%$ ), and esters ( 4 to $7 \%$ ). The increment of each type compounds by increasing the thickness of particleboards is shown in Table 2. Compared with $8 \mathrm{~mm}$ particleboard, the emission of esters and terpenes increased by $215 \%$ and $203 \%$, respectively, indicating that these chemical compounds were most sensitive to the thickness change.

Table 2. Increasing Level of Each Type of Compound at Exposure 60 Days

\begin{tabular}{cccc}
\hline $\begin{array}{c}\text { Compounds } \\
\text { type }\end{array}$ & $\begin{array}{c}\text { Increasing level of } \\
\text { VOCs }^{*} \text { from 0.6 to 0.8 } \\
\text { g/cm }\end{array}$ & $\begin{array}{c}\text { Increasing level of } \\
\text { VOCs }^{*} \text { density (\%) } \\
\text { thickness (\%) }\end{array}$ & $\begin{array}{c}\text { Increasing level of } \\
\text { VOCs* }\end{array}$ \\
\hline resin content $(\%)$ \\
\hline Aromatics & 75 & 65 & 100 \\
Alcohols & 12 & 102 & 124 \\
Aldehydes & 221 & 151 & 582 \\
Ketones & 81 & 105 & 258 \\
Terpenes & 149 & 203 & -48 \\
Alkanes & 68 & 111 & 72 \\
Esters & 233 & 215 & 306 \\
\hline
\end{tabular}

"VOCs: volatile organic compounds

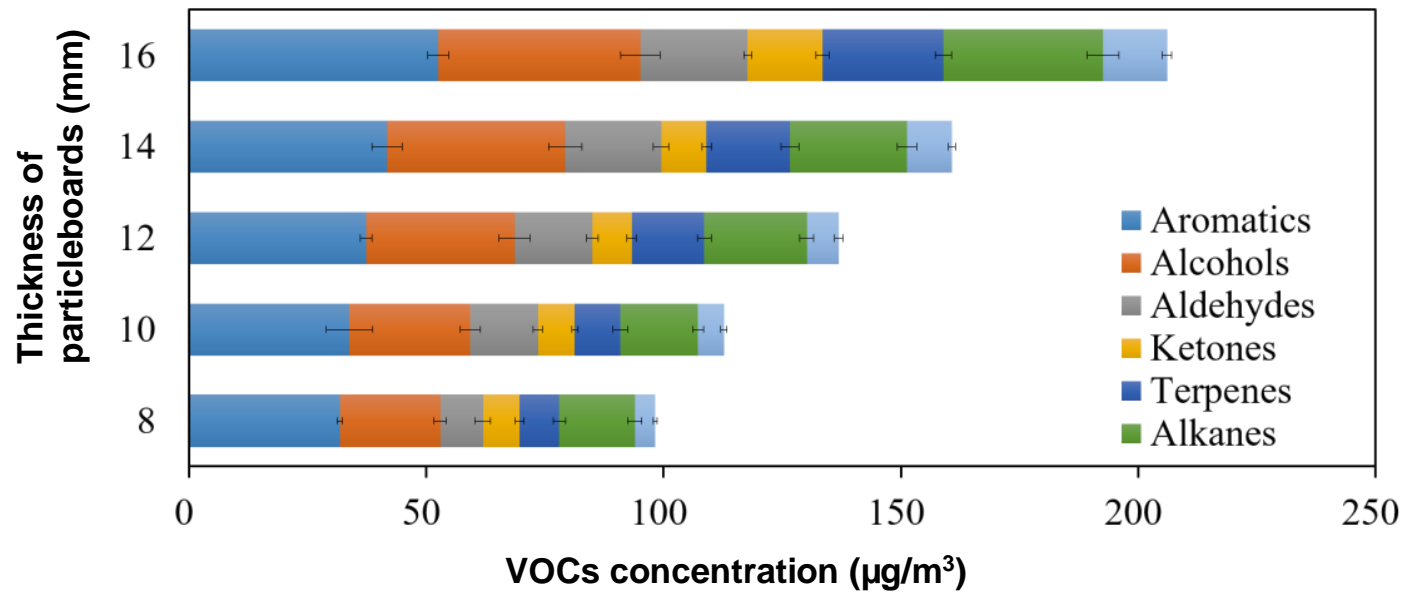

Fig. 6. Chemical compounds concentration of volatile organic compounds (VOCs) emission from five series of different thickness particleboards after exposure at room temperature for 60 days

The amounts of each compound in the TVOC emission of the particleboard manufactured with different resin content and exposure for 60 days are shown in Fig. 7. Most compounds were increased by adding resin content, but the opposite result was observed from terpenes. Aromatics was the highest content in the TVOC of each type particleboard (30 to 32\%), followed by alcohols (21 to 25\%), aldehydes ( 9 to $30 \%$ ), alkanes (15 to $18 \%$ ), ketones ( 8 to $13 \%$ ), esters ( 4 to $8 \%$ ), and terpenes ( 2 to $9 \%$ ). Table 2 shows the increment of each compound. Comparing the particleboards bonded with 7 and $11 \%$ resin content, terpenes were decreased by $48 \%$ by adding resin content, indicating that the emission of terpenes was most influenced by the content of wood particles (the density of the particleboard was kept at $0.7 \mathrm{~g} / \mathrm{cm}^{3}$ ). The increment levels of aldehydes, ketones, and esters showed high values; these chemical compounds were most sensitive to the resin content change. In addition, aromatics, alcohols, and alkanes obtained a positive increment 
by adding the resin content, implying that these compounds were also partly derived from the composition of UF adhesive, such as some auxiliaries (Wang and Gardner 1999).

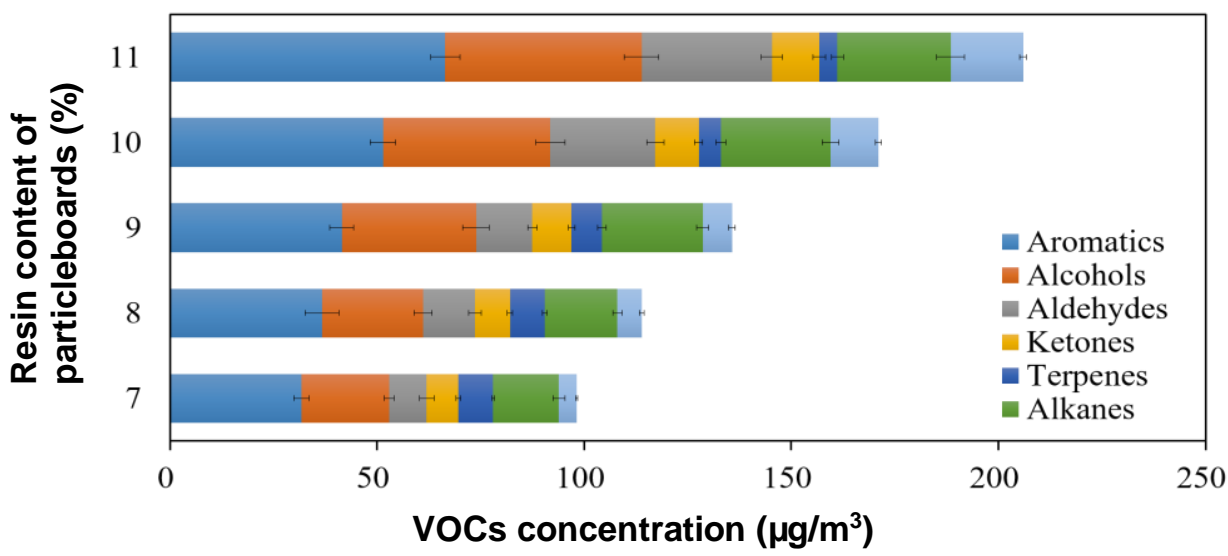

Fig. 7. Chemical compounds concentration of volatile organic compounds (VOCs) emission from five series of different resin content particleboards after exposure at room temperature for 60 days

The main detected compounds (having concentration more than $0.1 \mu \mathrm{g} / \mathrm{m}^{3}$ and detected more than 35 times.) in each chemical substance types are shown in Table 3.

Table 3. Main Compounds in Each Chemical Substances Type *

\begin{tabular}{|c|c|}
\hline Type of Compounds & VOCs Compounds \\
\hline Esters & Acetic acid, butyl ester \\
\hline \multirow{2}{*}{ Terpenes } & 2,4-Dimethylstyrene \\
\hline & Bicyclo[4.4.1]undeca-1,3,5,7,9-pentaene \\
\hline \multirow[t]{2}{*}{ Aldehydes } & Benzaldehyde \\
\hline & Nonanal \\
\hline \multirow{7}{*}{ Aromatics } & p-Xylene \\
\hline & 1,2,4-trimethyl-Benzene \\
\hline & 4-ethyl-1,2-dimethyl- Benzene \\
\hline & 1-methyl-4-(1-methylpropyl)-Benzene \\
\hline & Naphthalene \\
\hline & 2-methyl-Naphthalene \\
\hline & Ethylbenzene \\
\hline \multirow{3}{*}{ Alcohols } & 2-butoxy-Ethanol \\
\hline & 1-butoxy-2-Propanol \\
\hline & Benzyl Alcohol \\
\hline Ketones & Acetophenone \\
\hline \multirow{2}{*}{ Alkanes } & Tetradecane \\
\hline & Pentadecane \\
\hline
\end{tabular}

* The word "main" implies that the concentration was more than $0.1 \mu \mathrm{g} / \mathrm{m}^{3}$, and it was detected more than 35 times.

The ester compounds were mainly acetic acid butyl ester. This was possibly derived from the UF resin (Wang and Gardner 1999). Although the concentrations of ester increased obviously, the total amount was just 3 to $5 \%$. The terpenes were derived from wood elements, especially pine (Baumann et al. 1999, 2000); thus, the increasing terpene content was due to the addition of wood particles. Regarding aldehydes, these compounds 
are the main components of particleboard (Baumann et al. 1999; Hodgson et al. 2002; Costa et al. 2014). Hexanal, benzaldehyde, and nonanal were detected in all of the boards. The hexanal was considered from the wood elements (Hodgson et al. 2002), and benzaldehyde and nonanal was most possibly due to the curing or pyrolysis of UF resin (and Gardner 1999). The higher density, thickness, and resin content of particleboards caused more terpenes and aldehydes emission, and this was considered a primary reason for the increase in TVOC. However, the greatest proportion of TVOC were aromatics. The increase in aromatics was due to increasing of wood amount (Jensen et al. 2001).

\section{CONCLUSIONS}

1. The TVOC and VOCs emissions of the particleboard manufactured under different conditions were investigated in this research. As the exposure time was extended, the TVOC emission from each manufacture conditions of particleboards (density, thickness, resin content) were decreased. The higher density, thickness, and resin content of particleboard at each time of measurement caused a higher concentration of TVOC emission and exhibited a negative correlation on the TVOC emission level.

2. Based on the results of chemical composition analysis of TVOC derived from 60 exposure days, it could be found that the increasing of density, thickness and resin content caused an increment of the kinds of chemical substances, in addition, the aromatics were confirmed as the most compounds of TVOC.

3. The increasing level of esters, aldehydes, and ketones were most sensitive to the change of manufacture conditions. However, terpenes exhibited a positive increment by adding the density and thickness but a negative influence by increasing resin content. This result indicated that terpenes compounds in the TVOC were mostly derived from wood particles.

\section{ACKNOWLEDGMENTS}

The authors are grateful for financial support from Scientific Research Foundation of Nanjing Forestry University (GXL2018013).

\section{REFERENCES CITED}

Baumann, M. G. D., Batterman, S. A., and Zhang, G. Z. (1999). "Terpene emissions from particleboard and medium-density fiberboard products," Forest Prod. J. 49(1), 49-56.

Baumann, M. G. D., Lorenz, L. F., Batterman, S. A., and Zhang, G. Z. (2000). "Aldehyde emissions from particleboard and medium density fiberboard products," Forest Prod. J. 50(9), 75-82.

Brightman, H. S., Milton, D. K., Wypij, D., Burge, H. A., and Spengler, J. D. (2008). "Evaluating building-related symptoms using the US EPA BASE study results," Indoor Air 18(4), 335-345. DOI: 10.1111/j.1600-0668.2008.00557.x 
Costa, N. A., Ohlmeyer, M., Ferra, J., Magalhaes, F. D., Mendes, A., and Carvalho, L. (2014). "The influence of scavengers on VOC emissions in particleboards made from pine and poplar," Eur. J. Wood Prod. 72, 117-121. DOI: 10.1007/s00107-013-0761-9

Du, Z. J., Mo, J. H., and Zhang, Y. P. (2014). "Risk assessment of population inhalation exposure to volatile organic compounds and carbonyls in urban China," Environ. Int. 73, 33-45. DOI: 10.1016/j.envint.2014.06.014

Hodgson, A. T., Beal, D., and McIlvaine, J. E. R. (2002). "Sources of formaldehyde, other aldehydes and terpenes in a new manufactured house," Indoor Air 12(4), 235242. DOI: 10.1034/j.1600-0668.2002.01129.x

Jensen, L. K., Larsen, A., Molhave, L., Hansen, M. K., and Knudsen, B. (2001). "Health evaluation of volatile organic compound (VOC) emissions from wood and woodbased materials," Arch. Environ. Health 56, 419-432. DOI: 10.1080/00039890109604477

Jiang, C. J., Li, D. D., Zhang, P. Y., Li, J. G., Wang, J., and Yu, J. G. (2017). "Formaldehyde and volatile organic compound (VOC) emissions from particleboard: Identification of odorous compounds and effects of heat treatment," Build Environ. 117, 118-126. DOI: 10.1016/j.buildenv.2017.03.004

Jiang, T., Gardner, D. J., and Baumann, M. G. D. (2002). "Volatile organic compound emissions arising from the hot-pressing of mixed-hardwood particleboard," Forest. Prod. J. 52(11), 66-77.

Kim, S., and Kim, H. J. (2015). "Comparison of formaldehyde emission from building finishing materials at various temperatures in under heating system, ONDOL," Indoor Air 15(5), 317-325. DOI: 10.1111/j.1600-0668.2005.00368.x

Liang, W. H., Lv, M. Q., and Yang, X. D. (2016). "The combined effects of temperature and humidity on initial emittable formaldehyde concentration of a medium-density fiberboard," Build Environ. 98, 80-88. DOI: 10.1016/j.buildenv.2015.12.024

Liang, W. H., Yang, S., and Yang, X. D. (2015). "Long-term formaldehyde emissions from medium-density fiberboard in a full-scale experimental room: Emission characteristics and the effects of temperature and humidity," Environ. Sci. Technol. 49(17), 10349-10356. DOI: 10.1021/acs.est.5b02217

Lin, C. C., Yu, K. P., Zhao, P., and Lee, G. W. M. (2009). "Evaluation of impact factors on VOC emissions and concentrations from wooden flooring based on chamber tests," Build Environ. 44(3), 525-533. DOI: 10.1016/j.buildenv.2008.04.015

Liu, Y., Shen, J., and Zhu, X. D. (2010). "Influence of processing parameters on VOC emission from particleboards," Environ. Monit. Assess. 171(1-4), 249-254. DOI: 10.1007/s10661-009-1275-0

Navarrete, P., Kebbi, Z., Michenot, F., Lemonon, J., Rogaume, C., Masson, E., Rogaume, Y., and Pizzi, A. (2013). "A. Formaldehyde and VOCs emissions from bioparticleboards," J. Adhes. Sci. Technol. 27(7), 748-762. DOI:

10.1080/01694243.2012.727149

Norback, D. (2009). “An update on sick building syndrome,” Curr. Opin. Allergy Cl. 9, 55-59. DOI: 10.1097/ACI.0b013e32831f8f08

Salthammer, T., Mentese, S., and Marutzky, R. (2010). "Formaldehyde in the indoor environment," Chem. Rev. 110(4), 2536-2572. DOI: 10.1021/cr800399g

Smith, M. T. (2010). "Advances in understanding benzene health effects and susceptibility," Annu. Rev. Publ. Health 31, 133-148. DOI:

10.1146/annurev.publhealth.012809.103646 
Wang, W. L., and Gardner, D. J. (1999). "Investigation of volatile organic compound press emissions during particleboard production. Part 1. UF-bonded southern pine," Forest Prod. J49, 65-72.

Wolkoff, P. (2018). "Indoor air humidity, air quality, and health - An overview," Int. J. Hyg. Envir. Heal. 221(3), 376-390. DOI: 10.1016/j.ijheh.2018.01.015

Wu, Y., Tang, Q., Yang, F., Xu, L., Wang, X., and Zhang, J. (2019). "Mechanical and thermal properties of rice straw cellulose nanofibrils-enhanced polyvinyl alcohol films using freezing-and-thawing cycle method," Cellulose 26(5), 3193-3204, DOI: 10.1007/s10570-019-02310-6

Xiong, X. Q., Yuan, Y. Y., Fang, L., Liu, H., Wu, Z. H. (2018). "Status and development trends of intelligent manufacturing in China's furnishings industry," Forest. Prod. J. 68(3), 328-336.

Yrieix, C., Dulaurent, A., Laffargue, C., Maupetit, F., Pacary, T., and Uhde, E. (2010). "Characterization of VOC and formaldehyde emissions from a wood based panel: Results from an inter-laboratory comparison," Chemosphere 79(4), 414-419. DOI: 10.1016/j.chemosphere.2010.01.062

Zhao, Z. Y., Hayashi, S., Xu, W., Wu, Z. H., Tanaka, S., Sun, S. J., Zhang, M., Kanayama, K., and Umemura, K. (2018a). "A novel eco-friendly wood adhesive composed by sucrose and ammonium dihydrogen phosphate," Polymers 10(11), 1251-1265 DOI: 10.3390/polym10111251

Zhao, Z. Y., Miao, Y. F., Yang, Z. Q., Wang, H., Sang, R. J., Fu, Y. C., Huang, C. X., Wu, Z. H., Zhang, M., Sun, S. J., et al. (2018b). "Effects of sulfuric acid on the curing behavior and bonding performance of tannin-sucrose adhesive," Polymers 10(6), 651-664. DOI: 10.3390/polym10060651

Zheng, C. X., Yue, Y. Y., Gan, L., Xu, X. W., Mei, C. T., and Han, J. Q. (2019). "Highly stretchable and self-healing strain sensors based on nanocellulose-supported graphene dispersed in electro-conductive hydrogels," Nanomaterials 9(7), 937-953. DOI: 10.3390/nano9070937

Article submitted: October 24, 2019, Peer review completed: December 15, 2019; Revised version received: and accepted: December 18, 2019; Published: December 20, 2019.

DOI: 10.15376/biores.15.1.1074-1084 